\title{
Sistem Pemetaan Ruangan 2D Menggunakan Lidar
}

\author{
Senanjung Prayoga, Asti Budianto, Ardian Budi Kusuma Atmaja \\ Politeknik Negeri Batam \\ Mechatronics Engineering Study Program \\ Parkway Street, Batam Centre, Batam 29461, Indonesia \\ E-mail: senanjung@polibatam.ac.id, budianto.asti01@gmail.com, ardianbudi@polibatam.ac.id
}

\begin{abstract}
ABSTRAK
Agar dapat membantu pekerjaan dalam sistem pembuatan peta pada suatu ruangan yang memiliki tingkat bahaya yang tinggi, dibutuhkan sebuah robot yang dapat mengganti proses pembuatan peta. Sehingga robot tersebut harus memiliki sistem pemetaan 2D yang baik, agar dapat menggambarkan bentuk peta yang benar. Area berbentuk kotak dengan ukuran 2,44 m x 1,6 m yang dilengkapi labirin di dalamnya dipilih sebagai area penelitian. Permasalahan yang muncul adalah bagaimana cara mengukur sekeliling ruangan dan membentuk gambar peta ruangan yang diukur. Pada penelitian ini akan dikembangkan sistem pemetaan ruangan dengan menggunakan sensor lidar yang mampu melakukan pengukuran ruangan dengan jarak ukur panjang maksimal $6 \mathrm{~m}$ dan dapat berputar $360^{\circ}$. Pada penelitian ini terdapat mobile robot yang berfungsi untuk membawa sensor lidar untuk menelusuri ruangan, sehingga sistem pemetaan ruangannya mampu menggambarkan peta ruangan secara keseluruhan. Untuk input pembuatan peta didapat dari hasil proses sensor lidar berupa nilai jarak dan sudut. Hasil penelitian ini diharapkan menghasilkan sistem pemetaan 2 dimensi secara langsung di komputer dengan ukuran peta terhadap objek sebenarnya. Setelah penelitian dilakukan, hasil pemetaan dari software yang dibuat telah memiliki kesamaan bentuk dengan lapangan yang sebenarnya. Terdapat rata rata error pengukuran dengan menggunakan sensor LIDAR sebesar 0,87\%.
\end{abstract}

Kata kunci: lidar, 2D, pemetaan

\begin{abstract}
In order to assist the work in the system mapping in a room that has a high danger level, it needs a robot that can change the map-making process. So the robot should have a good 2D mapping system, in order to draw the correct map. Box-shaped with a size of $2.44 \mathrm{~m} \mathrm{x} 1.6 \mathrm{~m}$ equipped with the labyrinth is selected as an area of research. The problem is how the lidar sensor can measure the perimeter of the room and build a map of the room measured image. In this research will develop indoor mapping system using Lidar sensor capable of measuring the distance measuring room with a maximum length of $6 \mathrm{~m}$ and rotates $360^{\circ}$. In this study, there is a mobile robot that serves to bring the lidar sensor to search for a room, so the room mapping system was able to build a map of the room overall. For the input of map-making system obtained from the of process lidar sensor in distance and angle values. Results of this research are expected to produce 2-dimensional mapping system on the computer directly, with the actual size of the object map. Once the research is done, the results of the mapping software created has had a similar form with actual field. There is an average error measurement using LIDAR sensor by $0.87 \%$.
\end{abstract}

Keyword: lidar, mobile robot, mapping

\section{Pendahuluan}

Dalam sistem pemetaan pada ruangan suatu gedung, biasanya petugas akan melakukan pengukuran secara manual dan terjun langsung ke dalam ruangan. Petugas akan berkeliling melakukan pengukuran dengan rute tertentu melewati sejumlah titik lokasi ruangan yang dianggap rawan terhadap gangguan keamanan. Tugas ini tentunya mengandung resiko keselamatan terhadap petugas sendiri. Untuk mengurangi resiko tersebut, tugas pengukuran ruangan dapat digantikan oleh sebuah robot yang membawa sensor lidar di atasnya. Agar dapat membuat peta ruangan dengan benar, maka robot yang membawa sensor lidar harus memiliki sistem pemetaan ruangan yang bagus. Beberapa penelitian telah dilakukan untuk memecahkan permasalahan tersebut antara lain penelitian dengan melakukan pengukuran ruangan menggunkan sensor ping yang diputar menggunakan motor servo dan membentuk peta ruangan. Sensor yang digunakan untuk mengukur ruangan tidak bergerak berpindah tempat [1].

Untuk mengatasi permasalahan-permasalahan yang muncul pada penelitian-penelitian sebelumnya, maka pada penelitian ini akan dikembangkan sistem pemetaan ruangan dengan menggunakan sensor lidar yang mampu melakukan pengukuran ruangan dengan jarak ukur panjang $6 \mathrm{~m}$ dan berputar $360^{\circ}$. Pada penelitian ini terdapat robot yang berfungsi untuk 
membawa sensor lidar untuk menelusuri ruangan, sehingga sistem pemetaan ruangan pada penelitian ini mampu menggambarkan peta ruangan secara keseluruhan.

\section{Dasar Teori}

\subsection{Lidar}

LIDAR (Light detection and ranging) adalah sebuah teknologi sensor jarak jauh menggunakan properti cahaya yang tersebar untuk menemukan jarak dan informasi suatu objek dari target yang dituju. Metode untuk menentukan jarak suatu objek adalah dengan menggunakan pulsa laser. Prinsip keja sensor LIDAR adalah, sensor memancarkan cahaya sinar laser terhadap objek kemudian dipantulkan kembali terhadap sensor, sinar yang dipantulkan kemudian ditangkap dan di analisis oleh detector. Perubahan komposisi cahaya yang diterima dari sebuah target ditetapkan sebagai objek. Hasil dari proses lidar adalah berupa sudut dan panjang jarak yang terkena pantulan oleh objek [2].

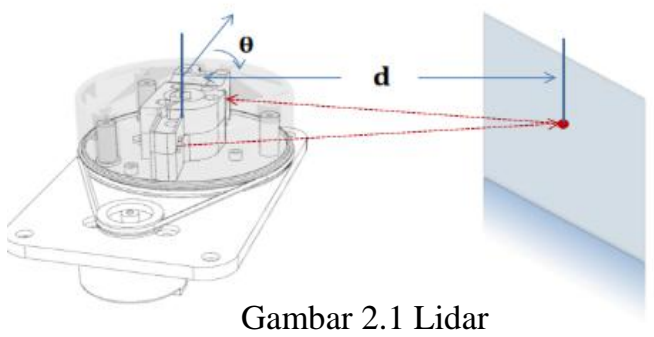

Gambar 2.1 menunjukkan cara kerja dari sensor lidar yang digunakan. Dari sensor lidar ini, akan didapatkan data keluaran berupa sudut $(\theta)$ dan berupa jarak (d).

\subsection{Rotary encoder}

Rotary Encoder adalah perangkat elektromekanik yang dapat memonitor gerakan dan posisi. Incremental encoder terdiri dari double track atau single track dan dua sensor yang disebut channel A dan B, sedangkan hubungan fasa antara channel A dan B menghasilkan arah putaran. Dengan menghitung jumlah pulsa yang terjadi terhadap resolusi piringan maka putaran dapat diukur. Untuk mengetahui arah putaran, dengan mengetahui channel mana yang leading terhadap channel satunya dapat kita tentukan arah putaran yang terjadi karena kedua channel tersebut akan selalu berbeda fasa seperempat putaran (quadrature signal). Seringkali terdapat output channel ketiga, disebut INDEX, yang menghasilkan satu pulsa per putaran berguna untuk menghitung jumlah putaran yang terjadi [3].

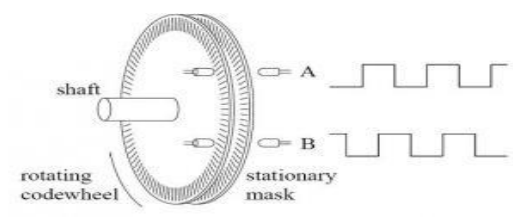

Gambar 2.2 encoder

\subsection{Bluetooth $\mathrm{HC} 05$}

HC - 05 adalah sebuah modul bluetooth SPP (Serial Port Protocol) yang mudah digunakan untuk komunikasi serial wireless yang mengonversi port serial ke bluetooth. Perangkat bluetooth ini menggunakan voltase $3,6 \mathrm{~V}-5,6$ dan serial port TX dan RX untuk berkomunikasi dengan arduino. Jadi, pesan yang diterima oleh perangkat bluetooth ini nantinya akan dikirimkan ke arduino secara serial sehingga cara pembacaannya melalui serial monitor untuk menangkap pesan yang diterima oleh perangkat bluetooth. HC-05 menggunakan modulasi bluetooth $\mathrm{V} 2.0$ + EDR(Enchanced Data Rate) 3 Mbps dengan memanfaatkan gelombang radio berfrekuensi $2,4 \mathrm{GHz}$ [4].

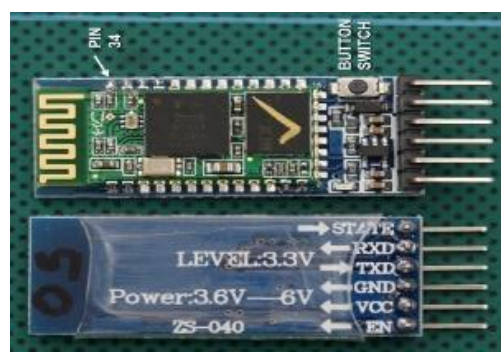

Gambar 2.3 HC 05

\subsection{Pemetaan $2 D$}

Pemetaan merupakan salah satu kemampuan yang saat ini harus ada pada sebuah mobile robot. Untuk mendapatkan posisi robot dalam koordinat kartasian, maka persamaan yang digunakan adalah [5]:

$$
\begin{aligned}
& X=S * \operatorname{Cos} \theta \\
& Y=S * \operatorname{Sin} \theta
\end{aligned}
$$

Dimana :

$\mathrm{X}=$ posisi robot dalam koordinat $\mathrm{X}$

$\mathrm{Y}=$ Posisi robot dalam koordinat $\mathrm{Y}$

$\mathrm{S}=$ Jarak tempuh robot

$\theta=$ Arah hadap pada mobile robot

Sedangkan untuk mendapatkan posisi terupdate dari robot ketika bergerak dalam koordinat kartesian, maka persamaan yang digunakan adalah:

$$
\begin{aligned}
& X_{X}=S_{X} * \operatorname{Cos} \theta_{X}+x_{X-1} \\
& Y_{X}=S_{X} * \operatorname{Sin} \theta_{X}+Y_{Y-1}
\end{aligned}
$$

Keterangan :

$X_{X}=$ Posisi terkini pada koordinat $\mathrm{X}$

$Y_{X}=$ Posisi terkini pada koordinat $\mathrm{Y}$

$S_{X}=$ Jarak tempuh

$\theta_{X}=$ Arah hadap

$x_{x-1}=$ Posisi koordinat X Sebelumnya

$Y_{Y-1}=$ Posisi koordinat $Y$ Sebelumnya 


\section{Perancangan Sistem}

\subsection{Rancangn Perangkat keras}

Secara umum, rancangan system yang digunakan seperti tampak pada gambar 3.1

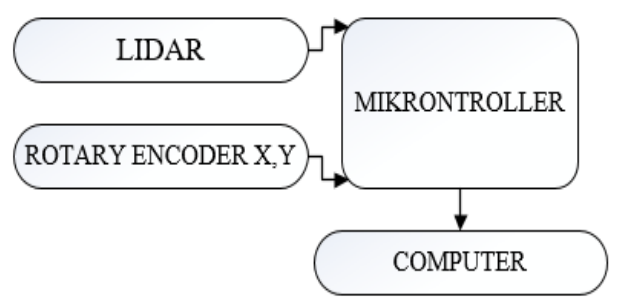

Gambar 3.1 Diagram sistem

Dari gambar diatas dapat dijelaskan bahwa sensor lidar dan sensor rotary encoder mengirim data ke mikrokontroller, kemudian data dari mikrokontroller dilanjutkan dikirim ke komputer untuk diproses pemetaan. Pengiriman data dari mikrokontroler ke komputer dilakukan dengan menggunakan fasilitas Bluetooth HC-05.

\subsection{Perancangan mekanik}

Desain robot Menggunakan 3 roda omni dimana 2 roda terpasang encoder sedangkan 1 roda lagi hanya sebagai roda bantu. Kontruksi robot pembawa lidar menggunakan papan acrylic sebagai base, dan sebuah mikrokontroller seperti terlihat pada gambar 3.2, sedangkan untuk bentuk aktualnya bisa dilihat pada gambar 3.3

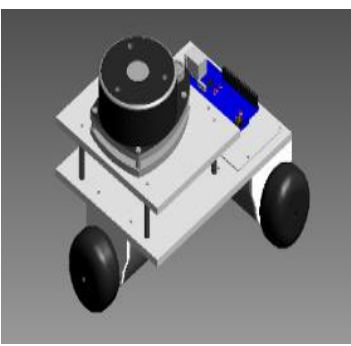

Gambar 3.2 Design

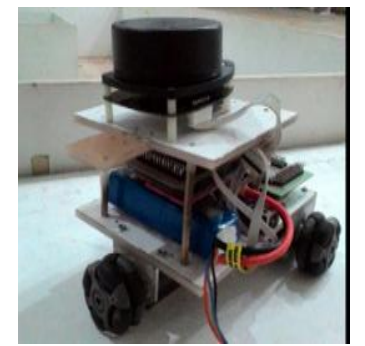

Gambar 3.3 Aktual

\subsection{Visualisasi Pemetaan}

Hasil pengukuruan ruangan yang telah dilakukan akan di tampilkan pada visual antar muka berupa gambar pemetaan ruangan. Komunikasi yang digunakan adalah komunikasi serial dengan bluetooth sebagai perantaranya. Setiap data Lidar berupa nilai jarak kemudian nilai sudut dan ditambahkan dengan data dari rotary encoder yang dikirim ke personal computer (PC), kemudian dihitung menggunakan persamaan 2.1 dan persamaan 2.2 yang akan menerjemahkan menjadi bentuk peta ruangan yang diukur.

Perancangan tampilan pada design visualisasi pemetaan dibuat dengan bantuan software visual studio C\# seperti pada gambar 3.4.

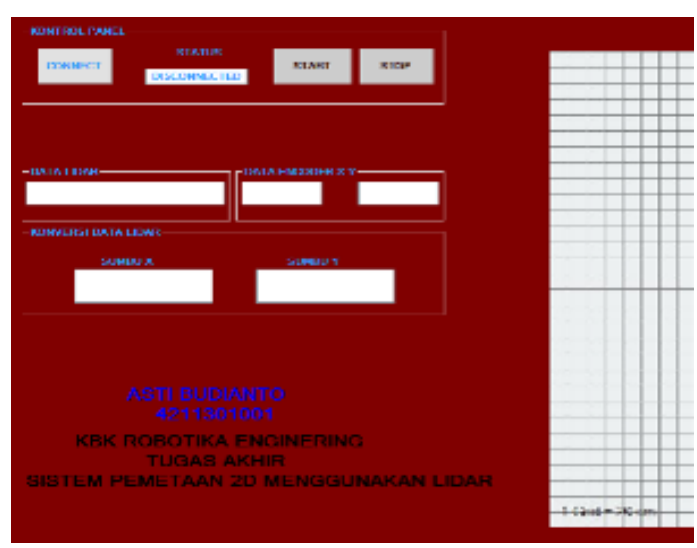

Gambar 3.4 Tampilan visualisai

\subsection{Instrumen penelitian}

Sistem pemetaan 2 dimensi menggunakan lidar diujikan pada arena pengujian dengan panjang 2,44 m dan lebar 1,6 $\mathrm{m}$ berbentuk kotak.

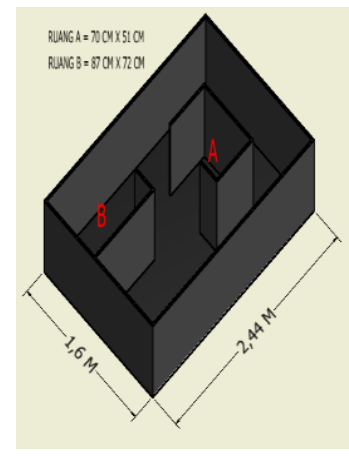

Gambar 3.5 design

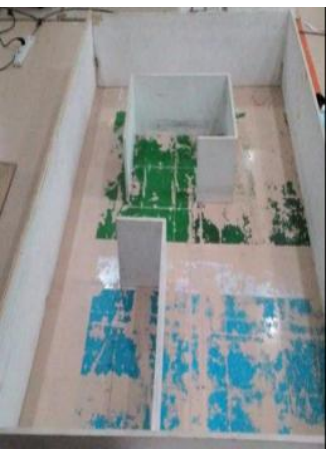

Gambar 3.6 Aktual

\section{Hasil dan Analisa}

Untuk mendapatkan hasil dan analisa maka diperlukan untuk melakukan beberapa pengujian. Adapun pengujian seperti dibawah ini:

\subsection{Pengujian rotary encoder}

Data pulsa encoder yang di ambil sebanyak 15 kali putaran roda pada encoder X dan encoder Y. Sehingga dapat pastikan apakah encoder yang di gunakan dalam keadaan baik dan akurasi. Dalam pengujian ini ketepatan dalam menentukan posisi roda omni dan badan encoder yang sejajar sangat diperlukan untuk mengetahui nilai pembacaan pulsa yang sebenarnya. Data hasil pengujian pengambilan pulsa encoder dapat di lihat pada tabel 4.1.

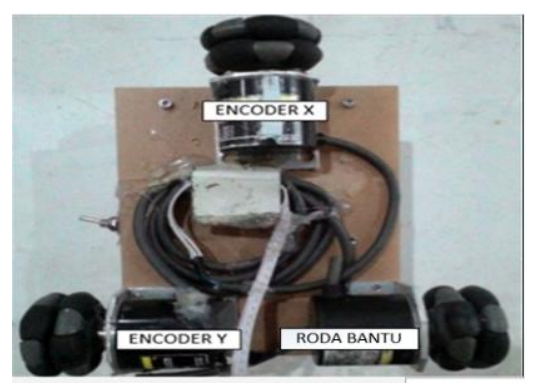

Gambar 4.1 Posisi encoder X, Y dan roda bantu 
Tabel 4.1 pulsa encoder

\begin{tabular}{|c|c|c|c|}
\hline NO & $\begin{array}{c}\text { Jumlah } \\
\text { putaran }\end{array}$ & $\begin{array}{c}\text { Jumlah pulsa } \\
\text { encoder Y }\end{array}$ & $\begin{array}{c}\text { Jumlah pulsa } \\
\text { encoder X }\end{array}$ \\
\hline 1 & 1 & 1430 & 1430 \\
\hline 2 & 2 & 2911 & 2910 \\
\hline 3 & 3 & 4330 & 4336 \\
\hline 4 & 4 & 5784 & 5783 \\
\hline 5 & 5 & 7184 & 7188 \\
\hline 6 & 6 & 8656 & 8633 \\
\hline 7 & 7 & 10090 & 10083 \\
\hline 8 & 8 & 11520 & 11521 \\
\hline 9 & 9 & 12977 & 12972 \\
\hline 10 & 10 & 14443 & 14441 \\
\hline 11 & 11 & 15886 & 15885 \\
\hline 12 & 12 & 17350 & 17348 \\
\hline 13 & 13 & 18769 & 18760 \\
\hline 14 & 14 & 20220 & 20221 \\
\hline 15 & 15 & 21635 & 21635 \\
\hline
\end{tabular}

Untuk membuktikan akurasi pembacaan sensor encoder di perlukan pembandingan data jarak yang di hasilkan encoder $\mathrm{X}$ dan encoder $\mathrm{Y}$ dengan pembacaan aktual menggunakan alat ukur penggaris. Panjang jarak yang di uji pengukurannya sepanjang $200 \mathrm{~cm}$ di karenakan arena pengujian pada penelitian ini sepanjang $200 \mathrm{~cm}$. Dalam pengambilan data ini ada bagian yang menjadi titik acuan dengan garis awal hingga garis akhir dengan menggerakan dudukan lidar secara lurus. Data perbandingan jarak terukur dangan jarak aktual dapat dilihat pada tabel 4.2.

Tabel 4.2 perbandiang jarak terukur encoder $\mathrm{X}, \mathrm{Y}$ dan jarak aktual

\begin{tabular}{|c|c|c|c|c|c|}
\hline No & $\begin{array}{c}\text { Aktual } \\
(\mathrm{cm})\end{array}$ & $\begin{array}{c}\text { Terukur } \\
\text { Y }(\mathrm{cm})\end{array}$ & $\begin{array}{c}\text { Terukur } \\
\mathrm{X}(\mathrm{cm})\end{array}$ & $\begin{array}{c}\text { Error } \\
\mathrm{Y}(\%)\end{array}$ & $\begin{array}{c}\text { Error } \\
\mathrm{X} \\
(\%)\end{array}$ \\
\hline 1 & 10 & 10.02 & 10.48 & 0.2 & 4.8 \\
\hline 2 & 20 & 19.55 & 20.37 & 2.25 & 1.85 \\
\hline 3 & 30 & 29.86 & 30.39 & 0.46 & 1.3 \\
\hline 4 & 40 & 39.6 & 40.56 & 1 & 1.4 \\
\hline 5 & 50 & 50.05 & 50.99 & 0.1 & 1.98 \\
\hline 6 & 60 & 60.66 & 60.69 & 1.1 & 1.15 \\
\hline
\end{tabular}

\begin{tabular}{|c|c|c|c|c|c|}
\hline 7 & 70 & 70.59 & 70.81 & 0.84 & 1.15 \\
\hline 8 & 80 & 79.55 & 80.74 & 0.56 & 0.92 \\
\hline 9 & 90 & 90.46 & 90.89 & 0.51 & 0.98 \\
\hline 10 & 100 & 101.14 & 100.87 & 1.14 & 0.87 \\
\hline 11 & 110 & 110.84 & 110.61 & 0.76 & 0.55 \\
\hline 12 & 120 & 120.44 & 120.56 & 0.36 & 0.46 \\
\hline 13 & 130 & 130.39 & 130.77 & 0.3 & 0.59 \\
\hline 14 & 140 & 140.95 & 140.53 & 0.67 & 0.37 \\
\hline 15 & 150 & 150.44 & 150.91 & 0.29 & 0.60 \\
\hline 16 & 160 & 160.5 & 159.99 & 0.31 & 0.006 \\
\hline 17 & 170 & 171.17 & 170.44 & 0.68 & 0.25 \\
\hline 18 & 180 & 181.05 & 180.75 & 0.58 & 0.41 \\
\hline 19 & 190 & 190.82 & 190.65 & 0.43 & 0.34 \\
\hline 20 & 200 & 200 & 200.72 & 0 & 0.36 \\
\hline & Rata - Rata Error & 0.384 & 0.605 \\
\hline
\end{tabular}

Dari hasil pengujian sistem sensor rotary encoder pada tabel 4.2 masih memiliki nilai error. Sesnsor rotari yang dirancang memiliki rata-rata persentase error untuk sumbu $\mathrm{X}$ adalah $0.605 \%$ sedangkan untuk sumbu Y adalah $0.384 \%$.

\subsection{Pengujian sensor lidar}

Pada penelitian ini menggunakan sensor lidar untuk mengukur luas ruangan dengan pembacaan tiap $1^{\circ}$ $360^{\circ}$ dengan type sensor RP LIDAR $360^{\circ}$ laser scaner. Tujuan pengujian sensor lidar untuk membandingkan bentuk peta yang dihasilkan oleh software RP LIDAR $360^{\circ}$ dengan software yang di buat sendiri oleh peneliti.

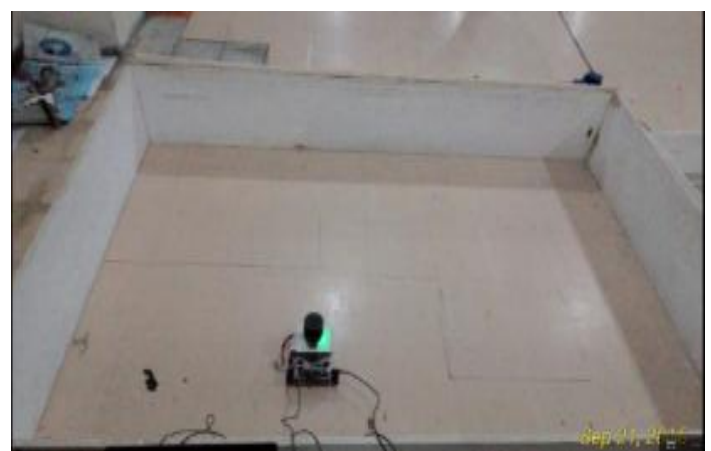

Gambar 4.2 pengujian pengukuran terhadap arena penelitian

Gambar 4.2 menunjukkan lapangan pengujian. Pengujian pemetaan ini di lakukan pada arena penelitan yang berbentuk kotak dengan ukuran panjang 2,44 m dan lebar 1,6 m. 


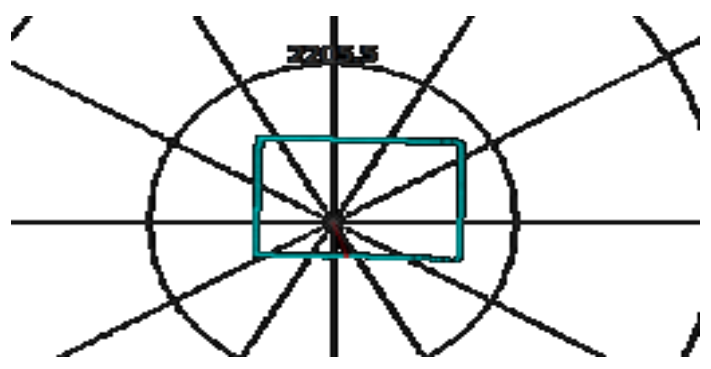

Gambar 4.3 software RP LIDAR

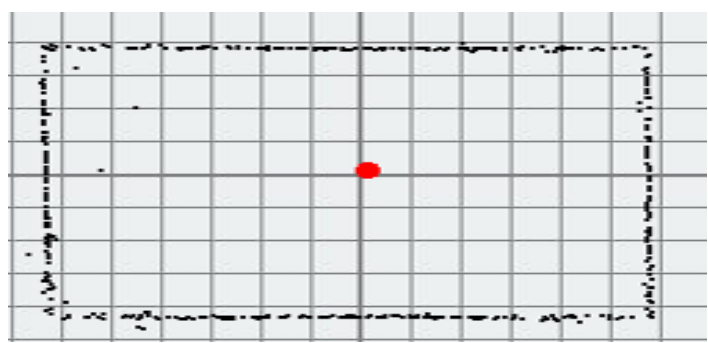

Gambar 4.4 software buatan peneliti

Berikut adalah tabel hasil pengukuran lapangan penelitian terhadap sensor lidar dimana nilai terukur berupa satuan $(\mathrm{mm})$. data yang di bandingkan berupa data hasil dari pengukuran aktual menggunakan software RP LIDAR terhadap software buatan peneliti pada tabel 4.3.

Tabel 4.3 hasil pengukuran sensor lidar

\begin{tabular}{|c|c|c|c|}
\hline $\begin{array}{c}\text { Sudut } \\
\left({ }^{\circ}\right)\end{array}$ & $\begin{array}{c}\text { Aktual } \\
(\mathrm{mm})\end{array}$ & $\begin{array}{c}\text { Terukur } \\
(\mathrm{mm})\end{array}$ & $\begin{array}{c}\text { Error } \\
(\%)\end{array}$ \\
\hline 0 & 1127 & 1127 & 0 \\
\hline 1 & 1125 & 1125 & 0 \\
\hline 2 & 1125 & 1125 & 0 \\
\hline 3 & 1125 & 1125 & 0 \\
\hline 4 & 1127 & 1127 & 0 \\
\hline 5 & 1129 & 1125 & 0,2458333 \\
\hline 6 & 1128 & 1129 & -0.089 \\
\hline 7 & 1133 & 1132 & 0.088 \\
\hline 8 & 1135 & 1135 & 0 \\
\hline 9 & 1134 & 1134 & 0 \\
\hline 10 & 1140 & 1137 & 0,1826389 \\
\hline 11 & 1142 & 1141 & 0.088 \\
\hline 12 & 1148 & 1145 & 0,18125 \\
\hline 13 & 1150 & 1149 & 0.087 \\
\hline 14 & 1153 & 1154 & -0.087 \\
\hline
\end{tabular}

\begin{tabular}{|c|c|c|c|}
\hline $\begin{array}{c}\text { Sudut } \\
\left({ }^{\circ}\right)\end{array}$ & $\begin{array}{c}\text { Aktual } \\
(\mathrm{mm})\end{array}$ & $\begin{array}{c}\text { Terukur } \\
(\mathrm{mm})\end{array}$ & $\begin{array}{c}\text { Error } \\
(\%)\end{array}$ \\
\hline 15 & 1160 & 1160 & 0.000 \\
\hline 16 & 1168 & 1167 & 0.086 \\
\hline 17 & 1172 & 1180 & -0.683 \\
\hline 18 & 1173 & 1173 & 0.000 \\
\hline 19 & 1180 & 1183 & -0.254 \\
\hline 20 & 1190 & 1206 & -1.345 \\
\hline 21 & 1201 & 1208 & -0.583 \\
\hline 22 & 1209 & 1209 & 0.000 \\
\hline 23 & 1129 & 870 & 22.941 \\
\hline 24 & 1220 & 1221 & -0.082 \\
\hline 25 & 1231 & 1233 & -0.162 \\
\hline Rata - rata error & $0,87 \%$ & \\
\hline
\end{tabular}

Dari hasil pengujian pengukuran terhadap arena penelitian di dapat rata rata error pengukuran sebesar $0,87 \%$. Eror ini terjadi karena software pengukuran yang dibuat oleh peneliti ketika mengolah data sudut dan jarak lidar terlalu banyak sehingga harus memotong pembacaan sudut lidar yang di peroleh sehingga menjadi lama dalam satu putaran motor lidar. Sehingga pengolahan data lidar menjadi lama dan terjadi penumpukan data yang membuat pembcaan lidar menjadi tidak akurasi dan terdapat beberapa error. Dan mengakibatkan adanya sedikit bercak hitam yang tidak beraturan pada hasil pemetaan seperti pada gambar 4.4 diatas.

\subsection{Hasil pemetaan lapangan statis}

Setelah dilakukan pengujian terhadap sensor rotary encoder dan RP LIDAR, telah bisa disimpulkan bahwa kedua sensor tersebut dalam kondisi baik dan bisa menghasilkan data yang akurat. Langkah selanjutnya adalah proses pemetaan ruangan. Berikut adalah hasil pemetaan dengan posisi sensor lidar diam ditempat tanpa bergerak menelusuri ruangan (stastis) dengan bentuk yang dirubah-rubah.

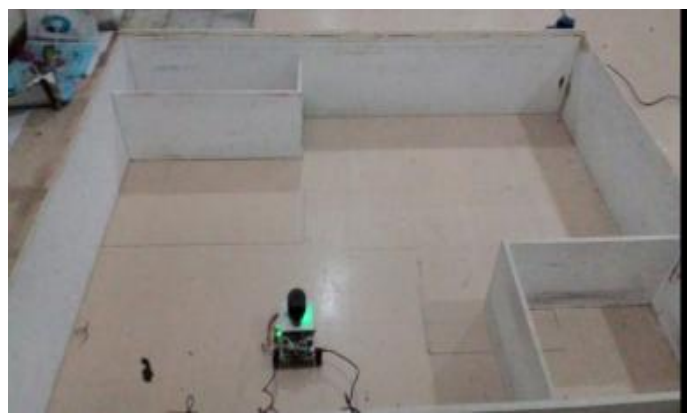

Gambar 4.5 Lapangan Pengujian 


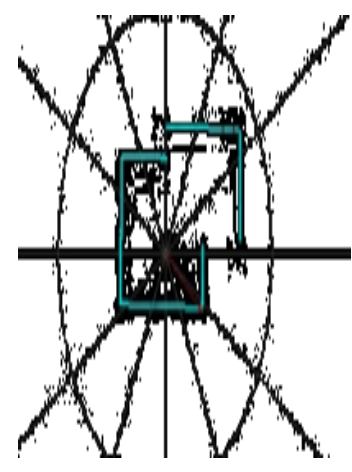

(a)

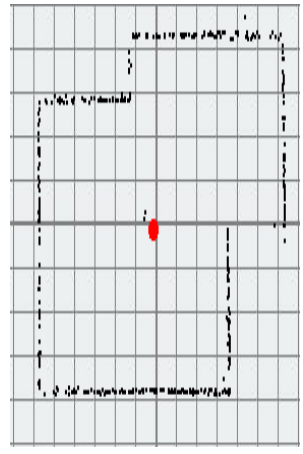

(b)
Gambar 4.6 (a) Hasil pemetaan software RPlidar

(b) Hasil pemetaan penelitian

Dari hasil percobaan yang telah dilakukan, dapat dilihat bahwa peta yang dihasilkan dengan menggunakan software buatan peneliti sudah menyerupai peta yang dihasilkan oleh software bawaan lidar. Titik-titik hitam yang membentuk garis merepresentasikan dinding ruangan yang dipetakan, sedangkan titik berwarna merah merupakan posisi sensor LIDAR berada. Jika pada software bawaan LIDAR, posisi sensor LIDAR ditandai dengan titik pusat lingkaran. Namun jika di perhatikan pada hasil pemetaan software RP lidar dan hasil pemetaan penelitian tidak dapat menggambarkan bentuk keseluruhan pada ruangan. Ini di akibatkan karena sensor lidar tidak dapat menjangkau daereah yang terhalang oleh sekat labirin. Sehinngga di perlukan untuk sensor lidar menelusuri ruangan agar menjangkau seluruh ruangan.

\subsection{Hasil pemetaan lapangan dinamis}

Selanjutnya dilakukan pembuatan peta seluruh ruangan dengan cara menggerakkan base pembawa sensor lidar untuk menelusuri ruangan (dinamis). Karena sensor lidar berubah posisi, maka posisi sensor lidar berubah terhadap koordinat awal $(0,0)$ juga berubah. Perubahan posisi ini akan dideteksi oleh sensor encoder. Diperlukan 2 sensor encoder untuk mendeteksinya, 1 encoder untuk perubahan sumbu $X$ dan 1 lagi untuk perubahan sumbu Y. Kemudian data yang dihasilkan digabungkan dengan data dari sensor encoder dengan menggunakan persamaan 2.3 untuk koordinat $\mathrm{X}$ dan 2.4 untuk koordinat $\mathrm{Y}$. Berikut adalah hasil pemetaan dengan posisi sensor lidar bergerak menelusuri ruangan (dinamis) dengan bentuk ruangan yang dirubah-rubah.

Setelah dilakukan percobaan pemetaan seluruh ruangan (dinamis), dari peta yang dihasilkan bisa dilihat bahwa dinding ruangan terlihat bergeser, khususnya seperti yang terlihat pada gambar 4.7 (b). Hal ini dikarenakan pembacaan encoder yang bergeser dan terdapat error pada jarak yang di tempuh oleh sensor encoder, dimana error ini telah di jelaskan pada tabel 4.2 Perbandingan jarak terukur encoder $\mathrm{X}, \mathrm{Y}$ dan jarak aktual. Sehingga mempengaruhi pembentukan peta karena berdasarkan rumus 2.3 dan 2.4, pembentukan peta juga dipengaruhi oleh pembacaan sensor encoder.

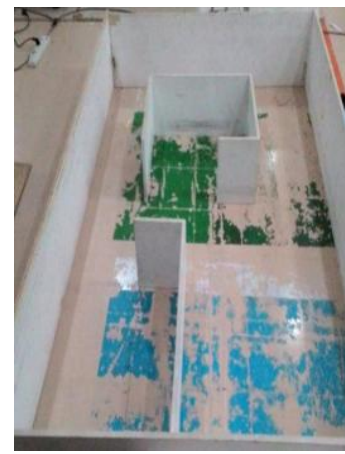

(a)

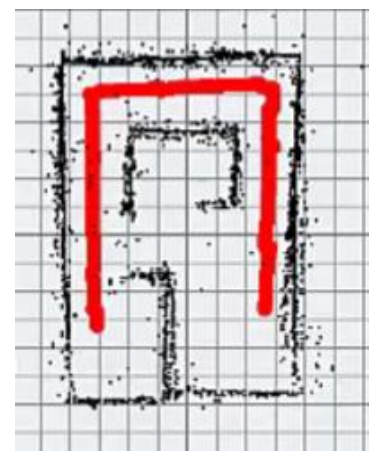

(b)
Gambar 4.7 (a) Arena pengujian

(b) Hasil pemetaan penelitian

Pembacaan encoder yang bergeser adalah dikarenakan pemilihan roda yang kurang tepat, yaitu roda omniwheel yang digunakan memiliki roller yang besar, sehingga bisa menyebabkan rawan terjadi pergeseran yang tidak diinginkan.

\section{Kesimpulan}

1. Dengan menggunakan persamaan 2.1 dan 2.2 telah dapat membuat peta ruangan secara langsung di komputer

2. Hasil pemetaan dari software yang dibuat telah memiliki kesamaan bentuk dengan lapangan yang sebenarnya.

3. Proses mengaplikasikan teknik pemetaan secara otomatis dapat berjalan dengan baik di dalam software yang telah dibuat.

Pada penelitian selanjutnya akan dibuat sistem pemetaan dan lokalisasi posisi robot yang sudah bisa bergerak secara otomatis. Agar bisa membuat robotnya bergerak secara otomatis, maka diperlukan metode tambahan yaitu pencarian jalur. Pencarian jalur ini bisa menggunakan metode path finder maupun metode $\mathrm{A}^{*}$.

\section{Daftar Pustaka}

[1] Ardi Yandoko "Pemetaan Ruangan Menggunakan Sonar" Buku Tugas Akhir Teknik Elektro Politeknik Negeri Batam, Batam, 2015.

[2] LowCost360 degre 2D Laser Scanner (Lidar) System, 1rd ed., RoboPeak team, 2014, pp.1-4.

[3] Ridwan., "Pengendalian Kecepatan Motor DC Dengan PD-Logika Fuzzy Terhadap Gangguan Pengereman Berbasis Mikrokontroller", Buku 
Tugas Akhir Diploma IV, Jurusan Mekatronika, Politeknik Negeri Batam, 2013.

[4] Martyn Currey. "arduino with HC-05(Zs-040) Bluetooth module-AT mode "internet http://www.martyncurrey.com/arduino-with-hc05-bluetooth-module-at-mode/ [DEC. 26, 2015].

[5] Janu anggoro, Ronny mardiyanto, Suwito, Pujiono., "Perancangan Sistem Pemetaan Otomatis Pada Mobile Robot Menggunakan Sensor Kinect dan Rotary Encoder", metode untuk mendapatkan posisi $\mathrm{X}$ dan $\mathrm{Y}^{\prime}$ Surabaya,2014. 